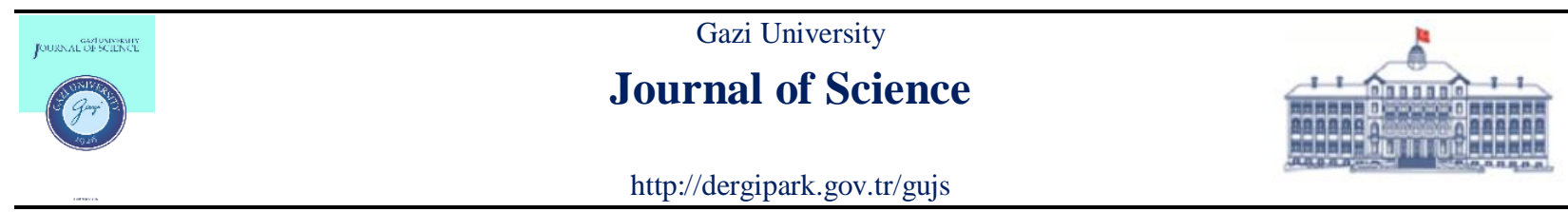

\title{
Co-pretreatment of Municipal Wastewater and Landfill Leachate by Chemical Coagulation Using Ferric Chloride and Aluminum Sulfate
}

\author{
Muslun Sara TUNC ${ }^{*}$ (D) \\ Firat University, Faculty of Engineering, Department of Environmental Engineering, 23119, Elazig, Turkey
}

\author{
Highlights \\ - Coagulation was applied for co-pretreatment of municipal wastewater and landfill leachate. \\ - Effects of parameters including coagulant type, coagulant dosage and $\mathrm{pH}$ were revealed. \\ - Coagulation removed $82 \%$ of COD and $99 \%$ of turbidity. \\ - Performance of ferric chloride coagulant was better than that of aluminum sulfate coagulant.
}

\begin{tabular}{l} 
Article Info \\
Received: 12/11/2019 \\
Accepted: 25/04/2020 \\
Keywords \\
\hline Alum \\
Coagulation \\
Ferric chloride \\
Landfill leachate \\
Municipal wastewater
\end{tabular}

\begin{abstract}
In this study, co-pretreatment of municipal wastewater (MW) and landfill leachate (LL) was investigated by means of coagulation using ferric chloride and aluminum sulfate. The effects of operating conditions on process performance were examined, which included $\mathrm{pH}$, coagulant type and coagulant dose. For both coagulants, the best removal efficiency was achieved at the initial $\mathrm{pH}$ of 5 . At this $\mathrm{pH}$, the removal efficiencies of chemical oxygen demand (COD), suspended solids (SS) and turbidity were $82 \%, \% 99$ and \%99, respectively with ferric chloride and $72 \%$, $98 \%$ and $98.5 \%$, respectively with aluminum sulfate. For the ratios ranging between 10:1 and 5:1 of MW to LL, the optimum dose was determined as $500 \mathrm{mg} / \mathrm{L}$ for both coagulants. When the ratio of MW to LL was reduced from 5:1 to 1:1, the coagulant dose required was raised from 500 to $1000 \mathrm{mg} / \mathrm{L}$ and the removal efficiency of pollutants reduced. Better removal efficiencies were achieved by ferric chloride in comparison to aluminum sulfate. The results revealed that coagulation could be applied as pretreatment for co-treatment of MW and LL.
\end{abstract}

\section{INTRODUCTION}

Due to the population growth and differences in habits of consumption, solid waste disposal has turned into a critical environmental issue [1]. Although priorities for minimizing solid waste disposal in solid waste management are reduction, reuse and recycling [2], a landfill is one of the widely employed methods in several countries [1], mainly owing to its economic advantages [3]. This method frequently leads to the generation of large quantities of leachate [4]. Leachate forms as a result of rainfall percolation through wastes, biochemical processes in cells of waste and the water content of wastes themselves [5]. Leachate formed in landfill sites is complex and very strong wastewater containing organic and inorganic contaminants [3,6], including chlorinated organic and inorganic salts, humic substances, ammonia nitrogen and heavy metals [7] and presents fluctuations in composition as a result of spatial and temporal variations [8]. Characteristics of leachate are influenced by various factors such as landfill age, waste type and composition, site hydrogeology, seasonal weather variation, dilution by rainfall, precipitation, and degree of decomposition within landfill [9]. The leachate generated constitutes potential threats for surface and groundwater resources and human and ecosystem health [10]. Due to its enormous impact on the quality of the environment, landfill leachate requires special attention and treatment [11]. If it is not treated properly, it leads to contamination of water resources and public health problems [12]. For this reason, it is essential to treat leachate [6]. 
Leachate management is one of the main challenges in landfills because the composition and quantity of leachate vary throughout the year. Establishing and operating a landfill leachate treatment plant on-site may be difficult owing to high costs and practical issues such as leachate availability throughout the year [13]. Thus, co-treatment of landfill leachate with municipal wastewater can be considered as an alternative option $[13,14]$. The co-treatment of leachate with municipal wastewater has been employed as an option to lower the costs of treatment units applied in landfills and operational costs [12]. Additionally, due to the variation of leachate nature over time, mixing of landfill leachate with municipal wastewater can be useful in sustaining the stability required for leachate treatment to meet the stringent discharge standards [13].

A variety of physico-chemical technologies such as coagulation-flocculation [15], air stripping [16,17], adsorption [18] and advanced oxidation processes [19], have been successfully applied for leachate treatment. Among them, coagulation/flocculation has been commonly employed as pre- or post-treatment for treating leachate, due to its efficiency, simplicity, easy implementation and reduced costs [20]. In this process, to destabilize the colloids and ensure agglomeration of small particles into larger settleable flocs, various compounds like ferric chloride, alum, polyaluminum chloride and/or polymers are included in wastewater [21]. The removal mechanism is mainly based on charge neutralization of negatively charged colloids by cationic hydrolysis products, followed by the combination of impurities in an amorphous hydroxide precipitate via flocculation [22]. Aluminum and iron salts are commonly applied as coagulants which are efficient for removing a wide range of pollutants [23]. Several parameters including $\mathrm{pH}$, coagulant dose and coagulant type impact process performance [24].

Several studies have reported leachate treatment by coagulation/flocculation using various coagulants. Amokrane et al. [25] employed coagulation/flocculation as pretreatment before reverse osmosis for stabilized landfill leachate treatment and obtained turbidity reduction of $97 \%$. In the research performed by Tatsi et al. [15], about $80 \%$ COD removal was achieved by ferric chloride for the partially stabilized leachates, whereas low COD removal (i.e. lower than 35\%) were obtained for the fresh leachate. Ntampou et al. [26] used coagulation with ferric chloride or polyaluminium chloride, as a pre- or post-treatment before or after ozonation respectively, and compared the efficiencies of the two processes. They obtained COD removal efficiencies up to $72 \%$ and $62 \%$ by addition of $7 \mathrm{mM} \mathrm{Fe}$ or $11 \mathrm{mM}$ Al respectively, corresponding to the optimum coagulant dosages. Assou et al. [27] investigated landfill leachate treatment by coagulation/flocculation process using aluminum and iron salts and reported that $67 \%$ and $60 \%$ of COD was removed by $\mathrm{FeCl}_{3}$ and $\mathrm{Al}_{2}\left(\mathrm{SO}_{4}\right)_{3}$, respectively and both $\mathrm{FeCl}_{3}$ and $\mathrm{Al}_{2}\left(\mathrm{SO}_{4}\right)_{3}$ were effective for removing COD. Nevertheless, there have been limited researches related to the co-treatment of leachate with municipal wastewater by coagulation using different coagulants. Verma and Kumar [28] studied coagulation/flocculation as a pre-treatment option for co-treatment of landfill leachate with municipal wastewater using ferric chloride along with polyacrylamide grafted gum ghatti. They reported that the best pre-treatment was achieved at 1:7 ratio of landfill leachate to municipal wastewater where 79\% COD, 93\% turbidity and 90\% TSS removal was recorded. In another study carried out by Verma and Kumar [13], cotreatment of landfill leachate with municipal wastewater was subjected to coagulation using alum as coagulant and electrocoagulation using aluminum plate as electrode. In the coagulation process, the best COD reduction (up to $80 \%$ ) was obtained with $3.8 \mathrm{~g} / \mathrm{L}$ alum at $1: 5$ ratio of landfill leachate to municipal wastewater.

In this context, the aim of this work is to examine the co-pretreatment of municipal wastewater and landfill leachate by coagulation using ferric chloride and aluminum sulfate. In the study, the effects of operating conditions including $\mathrm{pH}$, coagulant type and coagulant dose on chemical oxygen demand (COD), suspended solids (SS) and turbidity removals were examined.

\section{MATERIALS AND METHODS}

MW was taken from the municipal wastewater treatment plant in the province of Elazig, Turkey. LL was obtained from the landfill located in the province of Elazig, Turkey. The landfill was commissioned in 2009 [29]. MW and LL samples were filled in 10-L plastic containers. They were transferred to the laboratory right away, kept in the refrigerator at $4{ }^{\circ} \mathrm{C}$ and subsequently characterized. The characterization of MW and the LL is shown in Table 1. 
Table 1. Characterization of $M W$ and $L L$

\begin{tabular}{llll}
\hline Parameter & \multirow{2}{*}{ Unit } & \multicolumn{2}{l}{ Values } \\
\cline { 3 - 4 } & & MW & LL \\
\hline $\mathrm{pH}$ & - & $7.50-7.93$ & $7.80-7.93$ \\
Turbidity & $\mathrm{NTU}$ & $230-282$ & $82.7-87.1$ \\
$\mathrm{COD}$ & $\mathrm{mg} / \mathrm{L}$ & $780-800$ & $2600-2750$ \\
$\mathrm{SS}$ & $\mathrm{mg} / \mathrm{L}$ & $410-450$ & $348-374$ \\
$\mathrm{NH}_{4}-\mathrm{N}$ & $\mathrm{mg} / \mathrm{L}$ & $39.7-40.9$ & $1380-1430$ \\
$\mathrm{NO}_{3}-\mathrm{N}$ & $\mathrm{mg} / \mathrm{L}$ & $2.4-2.6$ & $31-32$ \\
\hline
\end{tabular}

The chemical coagulation experiments were performed in a jar test apparatus (Wise Stir jar test). Inorganic salts used as coagulants included ferric chloride $\left(\mathrm{FeCl}_{3} \cdot 6 \mathrm{H}_{2} \mathrm{O}\right)$ and aluminum sulfate $\left(\mathrm{Al}_{2}\left(\mathrm{SO}_{4}\right)_{3} \cdot 18 \mathrm{H}_{2} \mathrm{O}\right)$. Their concentrations were based on their hydrated forms. MW and LL samples taken from the refrigerator were left at ambient temperature for approximately $2 \mathrm{~h}$ prior to use. After this, the samples were fully agitated to re-suspend the settled solids prior to any coagulation test. Mixtures of MW and LL at different volumetric ratios were prepared. $500 \mathrm{~mL}$ sample consisting of MW and LL at different ratios was added into each of the beakers. In order to ascertain the optimum $\mathrm{pH}$, tests were performed at six different $\mathrm{pH}$ levels (pH 4-9) using the coagulant dose of $500 \mathrm{mg} / \mathrm{L}$ and the mixture of MW and LL at the volumetric ratio of 7.5:1. The initial $\mathrm{pHs}$ of the mixtures were set to the desired levels by diluted $\mathrm{H}_{2} \mathrm{SO}_{4}$ or $\mathrm{NaOH}$ solutions. Thereafter, ferric chloride and aluminum sulfate salts in different amounts were added into each of the glass beakers including a mixture of MW and LL at different volumetric ratios (10:1,7.5:1, 5:1, 2.5:1 and 1:1) at the optimum $\mathrm{pH}$ determined. The chemical coagulation procedure included three subsequent stages: rapid mixing, slow mixing and settling. The test conditions from studies carried out by different researchers, used coagulation/flocculation for leachate treatment, is summarized in Table 2. Accordingly, for this research, the test conditions were adopted as $160 \mathrm{rpm} 3 \mathrm{~min}$ for rapid mixing, $40 \mathrm{rpm} 20 \mathrm{~min}$ for slow mixing and $1 \mathrm{~h}$ for settling. After settling, the supernatant samples were taken from a point located below $4 \mathrm{~cm}$ of the liquid level via a pipette to avoid taking flock or foam with the sample. The COD, SS and turbidity of the supernatant were determined.

Table 2. Range of test conditions of coagulation/flocculation process stages applied for leachate treatment in literature

\begin{tabular}{llll}
\hline Process stages & Conditions & Range & Reference \\
\hline Rapid mixing & Speed (rpm) & $80-350$ & {$[22,30]$} \\
& Duration (min) & $1-5$ & {$[22,24]$} \\
Slow mixing & Speed (rpm) & $20-60$ & {$[3,24]$} \\
& Duration (min) & $15-30$ & {$[22,21]$} \\
Settling & Duration (min) & $30-60$ & {$[22,30]$} \\
\hline
\end{tabular}

COD and SS were analyzed based on Standard Methods [31]. Ammonia nitrogen $\left(\mathrm{NH}_{4}-\mathrm{N}\right)$ and nitrate nitrogen $\left(\mathrm{NO}_{3}-\mathrm{N}\right)$ analyses were performed using Merck Spectroquant ${ }^{\circledR}$ tests by a Nova 60 Spectroquant after the samples were passed from 0.45 - $\mu \mathrm{m}$ PTFE syringe filters. $\mathrm{pH}$ and turbidity were determined using a pH meter (Star Orion A111) and a turbidity meter (HACH TL2300), respectively.

The formula below was used to determine removal efficiency values:

Removal efficiency $(\%)=\frac{\left(C_{i}-C_{e}\right)}{C_{i}} \times 100$

where the $C_{i}$ and $C_{e}$ values represent the initial and effluent concentration of COD, SS and turbidity.

\section{RESULTS AND DISCUSSION}


In this work, the effects of the initial $\mathrm{pH}$ and the coagulant dose on COD, SS and turbidity removals from the mixture of MW and LL were investigated. Among various operating parameters affecting the performance of the coagulation process, $\mathrm{pH}$ plays a predominant role [21]. To determine the effect of the initial $\mathrm{pH}$ value on $\mathrm{COD}$, SS and turbidity removals, the initial $\mathrm{pH}$ of the samples was altered in the range of 4-9 while maintaining ferric chloride dose at $500 \mathrm{mg} / \mathrm{L}$ and $\mathrm{MW}$ to $\mathrm{LL}$ at the volumetric ratio of 7.5:1. $\mathrm{COD}$, SS and turbidity removal efficiencies obtained at different $\mathrm{pH}$ values using ferric chloride salt as the coagulant are shown in Figure 1. As seen in the figure, the highest removal percentages for COD, SS and turbidity were achieved at the initial $\mathrm{pH}$ of 5 . At this $\mathrm{pH}$ value, the removal efficiency values obtained for COD, SS and turbidity were $82 \%, 99 \%$ and $99 \%$, respectively. The results clearly indicated that the removal efficiencies were better in acidic rather than alkaline conditions. Under acidic conditions, ferric $\left(\mathrm{Fe}^{3+}\right)$ can hydrolyze and transform into a polynuclear cation with multiple positive charges, according to Equation (2). In Equation (2), $\mathrm{Fe}_{\mathrm{x}}(\mathrm{OH})_{\mathrm{y}}{ }^{(3 \mathrm{x}-\mathrm{y})}$ represents $\mathrm{Fe}(\mathrm{OH})^{2+}, \mathrm{Fe}_{2}(\mathrm{OH})_{2}{ }^{4+}, \mathrm{Fe}_{3}(\mathrm{OH})_{4}{ }^{5+}$ and some other species with positive charges [32]. These cations neutralized the colloids with negative charges and consequently increased the performance of the coagulation process [33]. Under basic conditions, $\mathrm{Fe}^{3+}$ forms $\mathrm{Fe}(\mathrm{OH})_{3}$ or $\mathrm{Fe}(\mathrm{OH})_{4}{ }^{-}$by reacting with $\mathrm{OH}^{-}$ions, as shown in Equations (3) and (4) [32]. Since $\mathrm{Fe}(\mathrm{OH})_{3}$ and $\mathrm{Fe}(\mathrm{OH})_{4}{ }^{-}$ have neutral and negative charges, they do not have an ability to neutralize colloids with negative charge [33]. In the work, $\mathrm{pH} 5$ was determined as the optimum $\mathrm{pH}$ value for coagulation by ferric chloride. This finding is consistent with previous studies [3,7,34,35].

$$
\begin{aligned}
& \mathrm{xFe}^{3+}+\mathrm{yH}_{2} \mathrm{O} \rightarrow \mathrm{Fe}_{\mathrm{x}}(\mathrm{OH})_{\mathrm{y}}{ }^{(3 \mathrm{x}-\mathrm{y})}+\mathrm{yH}^{+} \\
& \mathrm{Fe}^{3+}+3 \mathrm{OH}^{-} \rightarrow \mathrm{Fe}(\mathrm{OH})_{3} \\
& \mathrm{Fe}^{3+}+4 \mathrm{OH}^{-} \rightarrow \mathrm{Fe}(\mathrm{OH})_{4}^{-}
\end{aligned}
$$

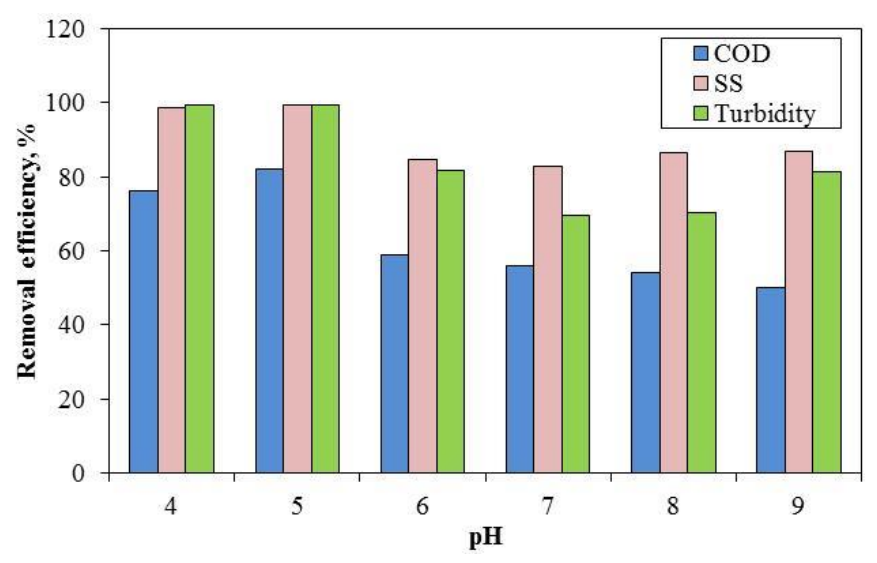

Figure 1. The influence of initial $\mathrm{pH}$ on treatment performance (Ferric chloride dosage: $500 \mathrm{mg} / \mathrm{L}$ and $M W: L L$ ratio $(7.5: 1))$

The coagulation process was then carried out using different coagulant doses at the initial $\mathrm{pH}$ of 5 . As known, a coagulant dose is one of the significant parameters that influence the performance of a coagulation process. Fundamentally, insufficient coagulant dose or overdose would lead to poor performance. To minimize the cost of dosing and achieve optimal performance in the coagulation process, it is important to specify the optimum dosage [36].

To examine the influence of ferric chloride dose on COD, SS and turbidity removal values from the mixture of MW and LL, ferric chloride doses ranging between 250 and $1500 \mathrm{mg} / \mathrm{L}$ were applied for the treatment of MW and LL mixture at different volumetric ratios (10:1-1:1) by keeping $\mathrm{pH}$ at the optimum condition (pH 5.0) and the results are shown in Figure 2. When the MW:LL ratio was altered in the range of 10:1 to $5: 1,500 \mathrm{mg} / \mathrm{L}$ was determined as the optimum ferric chloride dose for COD, SS and turbidity removals. This coagulant dose is less than that recorded by Verma and Kumar [28], which is $970 \mathrm{mg} / \mathrm{L}$ for the LL:MW ratio of 1:7 at $\mathrm{pH}$ 5. At the ferric chloride dose of $500 \mathrm{mg} / \mathrm{L}$, the highest COD removal was obtained as 
$82 \%$ at 7.5:1 and 5:1 ratios of the MW:LL at pH 5, while in the range of 10:1 to 5:1 of MW:LL, the maximum removal efficiency for both SS and turbidity was determined as $99 \%$. These results are higher than those achieved by Verma and Kumar [28], which were able to remove 79\%, 90\% and 93\% of COD, TSS and turbidity, respectively from LL-MW mixture by $\mathrm{FeCl}_{3}$ with flocculant at 1:7 ratio of LL-MW. COD removal values rose by increasing the coagulant dose up to the optimum dose and then decreased. This is because of the generation of flocs with a good nature at the optimum coagulant dose. However, in coagulant amounts under the optimum value, the flocs that are generated are small-sized and affect the settling speed of the sludge. In coagulant amounts above the optimum, both the generated flocs are smallsized and the capacity of rest can be influenced $[4,37]$. For the MW:LL ratio of $2.5: 1$ and 1:1, the optimum ferric chloride dose for COD, SS and turbidity removals was determined as $750 \mathrm{mg} / \mathrm{L}$ and $1000 \mathrm{mg} / \mathrm{L}$, respectively. $77 \%, 98 \%$ and $\% 98$ of COD, SS and turbidity were removed from MW-LL mixture by ferric chloride dose of $750 \mathrm{mg} / \mathrm{L}$ at 2.5:1 ratio, respectively, while their removal efficiency values were obtained to be $71 \%, 97 \%$ and $97 \%$, respectively by the ferric chloride dose of $1000 \mathrm{mg} / \mathrm{L}$ at the $1: 1$ ratio. Higher coagulant doses than the optimum coagulant dose did not lead to the improvement of process efficiency. When the coagulant was added to the mixture up to the optimum
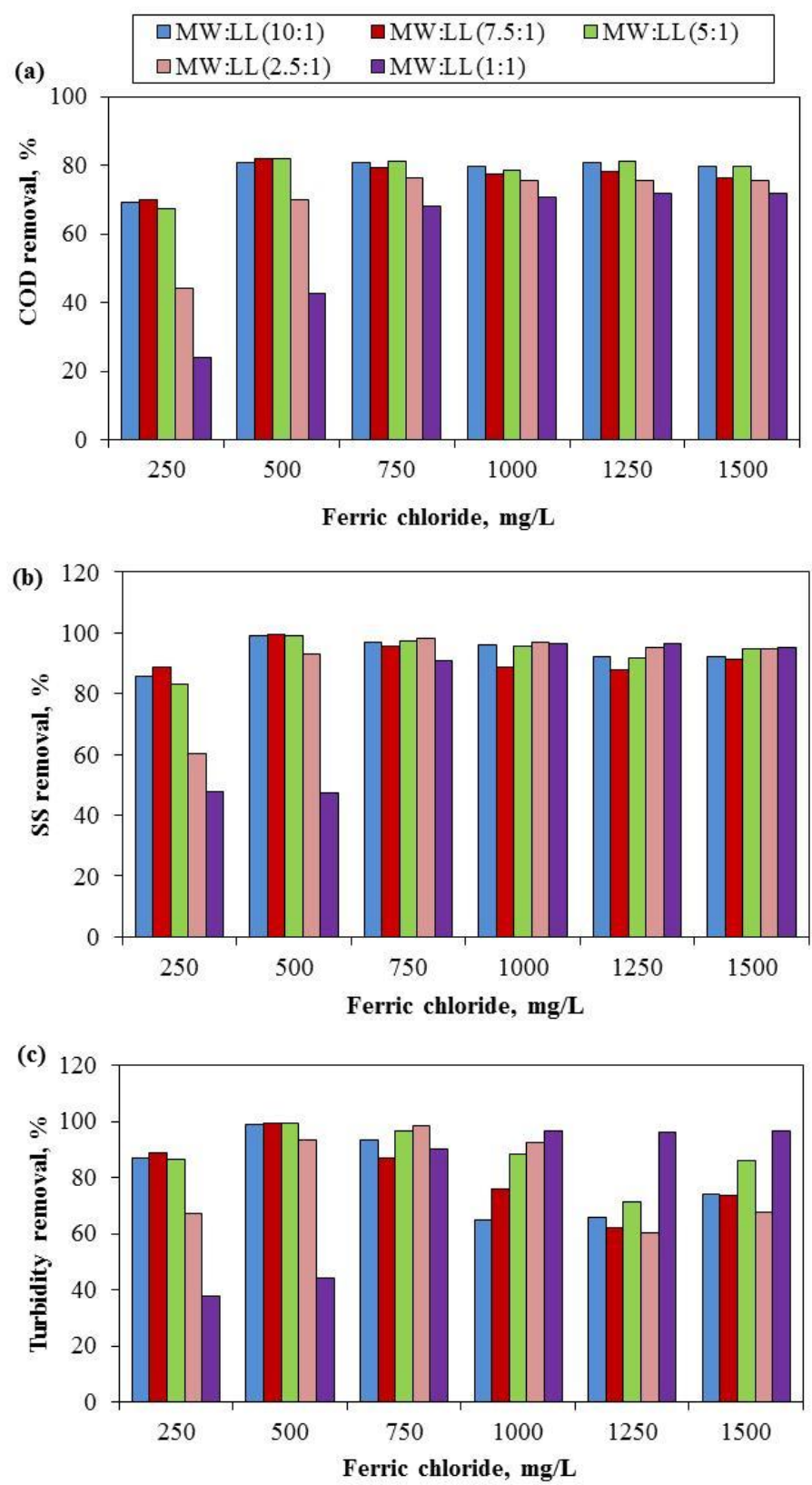
Figure 2. (a) COD, (b) SS and (c) turbidity removal efficiency at different dosages of ferric chloride at various $M W$-LL ratios and the initial $p H$ of 5

dose, $\mathrm{Fe}^{3+}, \mathrm{Fe}(\mathrm{OH})^{2+}$ and $\mathrm{Fe}(\mathrm{OH})_{2}{ }^{+}$with positive charges interacted with negative colloids, and their charges were neutralized, which increased the destabilization of colloids. However, above the optimum dose, colloids can absorb the cations and get positive charges, so, the colloids are stable again due to electrical repulsion $[3,38,39]$. In the study, when the coagulants were applied by higher than the optimum value, COD, SS and turbidity removal efficiencies decreased. This could be attributed to the restabilization of colloids [30]. At the optimum coagulant doses, significant variations were not observed in the SS and turbidity removal values at all ratios of MW-LL.

In order to specify the optimum $\mathrm{pH}$ range of aluminum sulfate, tests were conducted at different $\mathrm{pH}$ values ranging between 4 and 9 using the dose of $500 \mathrm{mg} / \mathrm{L}$ aluminum sulfate in the mixture of MW and LL at the volumetric ratio of 7.5:1. Using alum salt as a coagulant, the removal efficiencies obtained at different $\mathrm{pH}$ values are presented in Figure 3. As seen in this figure, $\mathrm{pH}$ played a crucial role in the removal of COD, SS and turbidity. Similar to the coagulation of ferric chloride, the maximum removal efficiency values were also achieved at the initial $\mathrm{pH}$ of 5 for the aluminum sulfate coagulant. At this optimum $\mathrm{pH}$ value, the maximum removal efficiency values for COD, SS and turbidity were determined to be $72 \%, 98 \%$ and $98.5 \%$, respectively. This can be clarified by the hydrolysis of $\mathrm{Al}_{2}\left(\mathrm{SO}_{4}\right)_{3}$. The hydrolyzed products of $\mathrm{Al}_{2}\left(\mathrm{SO}_{4}\right)_{3}$ are $\mathrm{Al}^{3+}$ and $\mathrm{Al}(\mathrm{OH})^{2+}$. With an increase in $\mathrm{pH}$, the hydrolyzed products of the aluminum salt transfer from the species with higher positive charges to the species with lower positive charges [32]. Bashir et al. [35], using alum coagulant, also obtained the highest removal percentage of pollutants in landfill leachate at the optimum $\mathrm{pH}$ of 5 .

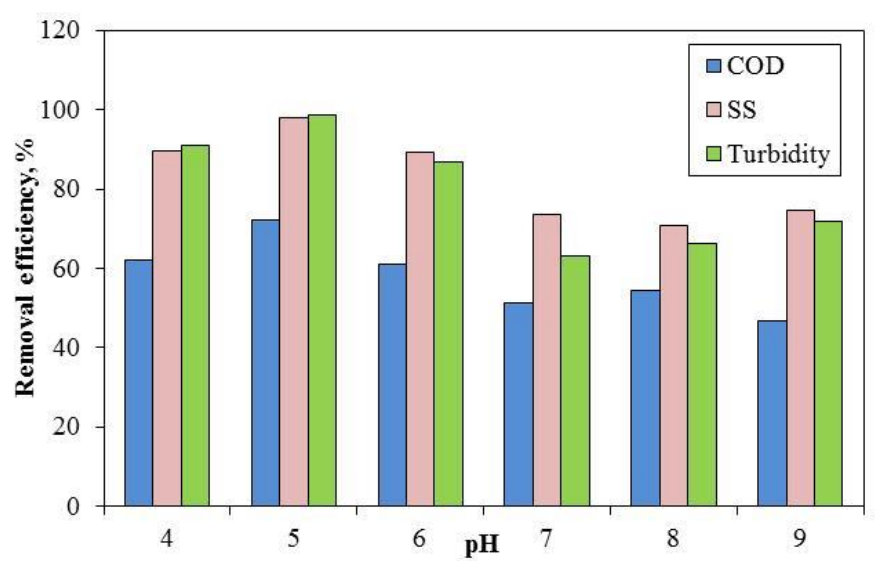

Figure 3. The influence of initial $\mathrm{pH}$ on treatment performance (alum dosage: $500 \mathrm{mg} / \mathrm{L}$ and $\mathrm{MW}: \mathrm{LL}$ ratio $(7.5: 1))$

Similar to the ferric chloride experiments, the varying aluminum sulfate doses $(250-1500 \mathrm{mg} / \mathrm{L})$ were applied for the treatment of MW and LL mixtures at different volumetric ratios (10:1-1:1) by keeping the $\mathrm{pH}$ at the optimum condition ( $\mathrm{pH}$ 5.0), and the results are shown in Figure 4. When the MW:LL ratio was changed in the range of 10:1 to 5:1, the optimum aluminum sulfate dose for COD, SS and turbidity removals was determined as $500 \mathrm{mg} / \mathrm{L}$. This optimum coagulant dose is lower than that recorded by Verma and Kumar [13], which is $3800 \mathrm{mg} / \mathrm{L}$ and $3300 \mathrm{mg} / \mathrm{L}$ alum for the maximum removal of COD and turbidity, respectively at 1:5 ratio of the LL:MW at pH 6. At the ferric chloride dose of $500 \mathrm{mg} / \mathrm{L}$, the highest removal efficiencies of COD, SS and turbidity were obtained as 73\% at 10:1 ratio of the MW:LL, 98\% at 7.5:1 of the MW:LL and 98.5\% at 10:1 and 7.5:1 of the MW:LL, respectively. For the MW:LL ratio of 2.5:1, the optimum aluminum sulfate dose for COD, SS and turbidity removals was determined as $750 \mathrm{mg} / \mathrm{L}$, obtaining removal rates of $65 \%, 94 \%$ and $\% 95$, respectively. For the MW:LL ratio of 1:1, The optimum aluminum sulfate dose was determined as $1500 \mathrm{mg} / \mathrm{L}$ for COD while the same value was $1250 \mathrm{mg} / \mathrm{L}$ for SS and turbidity, removing $63 \%, 88 \%$ and $89 \%$ of COD, SS and turbidity, respectively. Similar to the coagulation of ferric chloride, the treatment efficiency of aluminum sulfate increased with the dose in a certain range. When the dose of aluminum sulfate exceeded the optimum dose, this reduced the efficiency 
of treatment. The reason was similar to that of ferric chloride. As reported by the previous studies, ferric chloride was more effective than aluminum sulfate for removing organic matter in the treatment of landfill leachate $[15,25,32,40]$.
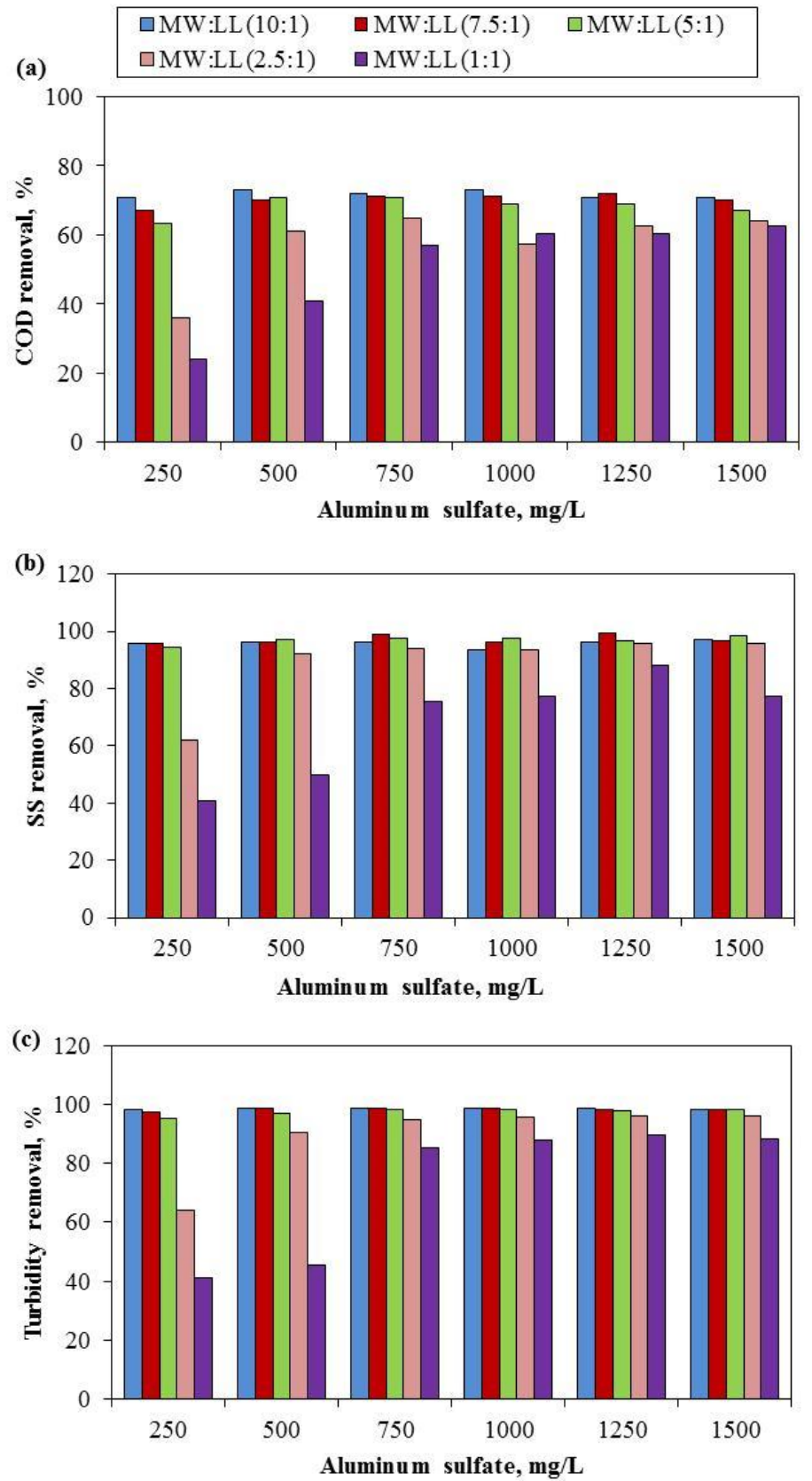

Figure 4. (a) COD, (b) SS and (c) turbidity removal efficiency at different dosages of aluminum sulfate at various $M W$-LL ratios and the initial $p H$ of 5

\section{CONCLUSIONS}

Co-treatment of MW and LL mixtures at different ratios was investigated in the coagulation experiment that included ferric chloride and aluminum sulfate salts as coagulants. Different doses of the ferric chloride and aluminum sulfate salts at the initial $\mathrm{pH}$ value of 5 were tested for COD, SS and turbidity removal at different ratios of MW to LL. At the ratios ranging between 10:1 and 5:1 of MW to LL, respectively 82\%, $99 \%$ and $99 \%$ of COD, SS and turbidity were removed using the optimum ferric chloride dose of $500 \mathrm{mg} / \mathrm{L}$, while respectively $71 \%, 97 \%$ and $97 \%$ of COD, SS and turbidity were removed using the optimum aluminum sulfate dose of $500 \mathrm{mg} / \mathrm{L}$. When the volumetric ratio of the MW to LL mixture was reduced from 
5:1 to 1:1, the required coagulant dose increased, and the removal of impurities from the mixture decreased. The initial $\mathrm{pH}$ and coagulant dose played an important role in the treatment process. In comparison to aluminum sulfate, better removal efficiency values were achieved by ferric chloride. The experimental findings that were obtained in this study demonstrated that coagulation could be utilized as a pretreatment method for the combined treatment of municipal wastewater and landfill leachate.

\section{CONFLICTS OF INTEREST}

No conflict of interest was declared by the author.

\section{REFERENCES}

[1] Veli, S., Öztürk, T., Dimoglo, A., "Treatment of municipal solid wastes leachate by means of chemical- and electro-coagulation", Separation and Purification Technology, 61(1): 82-88, (2008).

[2] Martins, T.H., Souza, T.S.O., Foresti, E., "Ammonium removal from landfill leachate by clinoptilolite adsorption followed by bioregeneration", Journal of Environmental Chemical Engineering, 5(1): 63-68, (2017).

[3] Amor, C., De Torres-Socias, E., Peres, J. A., Maldonado, M. I., Oller, I., Malato, S., Lucas, M.S., "Mature landfill leachate treatment by coagulation/flocculation combined with Fenton and solar photo-Fenton processes", Journal of Hazardous Materials, 286: 261-268, (2015).

[4] Abood, A.R., Bao, J., Dua, J., Zheng, D., Luo, Y., "Non-biodegradable landfill leachate treatment by combined process of agitation, coagulation, SBR and filtration", Waste Management, 34(2): 439447, (2014).

[5] Renou, S., Givaudan, J.G., Poulain, S., Dirassouyan, F., Moulin, P., "Landfill leachate treatment: Review and opportunity", Journal of Hazardous Materials, 150(3): 468-493, (2008).

[6] Moradi, M., Ghanbari, F., "Application of response surface method for coagulation process in leachate treatment as pretreatment for Fenton process: Biodegradability improvement", Journal of Water Process Engineering, 4: 67-73, (2014).

[7] Adlan, M.N., Palaniandy, P., Aziz, H.A., "Optimization of coagulation and dissolved air flotation (DAF) treatment of semi-aerobic landfill leachate using response surface methodology (RSM)", Desalination, 277(1-3): 74-82, (2011).

[8] Mesi (Dizdari), A., Kopliku, D., "Seasonal phyto- and genotoxicity monitoring of municipal landfill leachate on Allium cepa roots", Journal of Environmental Protection and Ecology, 15(4): 1671-1679, (2014).

[9] Luo, H., Zeng, Y., Cheng, Y., He, D., Pan, X., "Recent advances in municipal landfill leachate: A review focusing on its characteristics, treatment, and toxicity assessment", Science of The Total Environment, 703: 135468, (2020).

[10] Sackey, L.N.A., Kočí, V., van Gestel, C.A.M, "Ecotoxicological effects on Lemna minor and Daphnia magna of leachates from differently aged landfills of Ghana", Science of The Total Environment, 698: 134295, (2020).

[11] Malinovic, B.N., Djuricic, T., Bjelic, D., "Selection and consumption of electrode material for electrocoagulation of landfill leachate", Journal of Environmental Protection and Ecology, 18(1): 313-322, (2017). 
[12] de Albuquerque, E.M., Pozzi, E., Sakamoto, I.K., Jurandyr, P., "Treatability of landfill leachate combined with sanitary sewage in an activated sludge system", Journal of Water Process Engineering, 23: 119-128, (2018).

[13] Verma, M., Kumar, R.N., "Coagulation and electrocoagulation for co-treatment of stabilized landfill leachate and municipal wastewater", Journal of Water Reuse Desalination, 8(2): 234-243, (2018).

[14] Ranjan, K., Chakraborty, S., Verma, M., Iqbal, J., Kumar, R.N., "Co-treatment of old landfill leachate and municipal wastewater in sequencing batch reactor (SBR): effect of landfill leachate concentration", Water Quality Research Journal of Canada, 51(2): 377-387, (2016).

[15] Tatsi, A.A., Zouboulis, A.I., Matis, K.A., Samaras, P., "Coagulation-flocculation pretreatment of sanitary landfill leachates", Chemosphere, 53: 737-744, (2003).

[16] Ozturk, I., Altinbas, M., Koyuncu, I., Arikan, O., Gomec-Yangin, C., “Advanced physico-chemical treatment experiences on young municipal landfill leachates", Waste Management, 23: 441-446 (2003).

[17] Calli, B., Mertoglu, B., Inanc, B., "Landfill leachate management in Istanbul: applications and alternatives", Chemosphere, 59: 819-829 (2005).

[18] Rodríguez, J., Castrillón, L., Marañón, E., Sastre, H., Fernández, E., "Removal of nonbiodegradable organic matter from landfill leachates by adsorption", Water Research, 38: 3297-3303, (2004).

[19] Zazouli, M.A., Yousefi, Z., Eslami, A., Ardebilian, M.B., "Municipal solid waste landfill leachate treatment by Fenton, photo-Fenton and Fenton-like processes: effect of some variables", Iranian Journal of Environmental Health Science and Engineering, 9: 3 (2012).

[20] Bakraouy, H., Souabi, S., Digua, K., Dkhissi, O., Sabar, M., Fadil M., "Optimization of the treatment of an anaerobic pretreated landfill leachate by a coagulation-flocculation process using experimental design methodology", Process Safety and Environmental Protection, 109: 621-630, (2017).

[21] Kim, S.-C., "Application of response surface method as an experimental design to optimize coagulation-flocculation process for pre-treating paper wastewater", Journal of Industrial and Engineering Chemistry, 38: 93-102, (2016).

[22] Ghafari, S., Aziz, H.A., Isa, M.H., Zinatizadehd, A.A., "Application of response surface methodology (RSM) to optimize coagulation-flocculation treatment of leachate using polyaluminum chloride (PAC) and alum", Journal of Hazardous Materials, 163(2-3): 650-656, (2009).

[23] Duan, J., Gregory, J., "Coagulation by hydrolysing metal salts", Advances in Colloid and Interface Science, 100-102: 475-502, (2003).

[24] Liu, X., Li, X.-M., Yang, Q., Yue, X., Shen, T.-T., Zheng, W., Luo, K., Su, Y.-H., Zeng, G.-M., "Landfill leachate pretreatment by coagulation-flocculation process using iron-based coagulants: Optimization by response surface methodology", Chemical Engineering Journal, 200-202: 39-51, (2012).

[25] Amokrane, A., Comel, C., Veron, J., "Landfill leachates pretreatment by coagulation-flocculation", Water Research, 31: 2775-2782, (1997).

[26] Ntampou, X., Zouboulis, A.I., Samaras, P., "Appropriate combination of physicochemical methods (coagulation/flocculation and ozonation) for the efficient treatment of landfill leachates", Chemosphere, 62: 722-730, (2006). 
[27] Assou, M., El Fels, L., El Asli, A., Fakidi, H., Souabi, S., Hafidi, M., "Landfill leachate treatment by a coagulation-flocculation process: effect of the introduction order of the reagents", Desalination and Water Treatment, 57: 21817-21826, (2016).

[28] Verma, M., Kumar, R.N., "Can coagulation-flocculation be an effective pre-treatment option for landfill leachate and municipal wastewater co-treatment?", Perspectives in Science, 8: 492-494, (2016).

[29] Topal, M., Arslan Topal, E.I., Determination and monitoring of tetracycline and degradation products in landfill leachate, Clean - Soil, Air, Water, 44 (4): 444-450, (2016).

[30] Aziz, H.A., Alias, S., Adlan, M.N., Faridah, Asaari, A.H., Zahari, M.S., "Colour removal from landfill leachate by coagulation and flocculation processes", Bioresource Technology, 98: 218-220, (2007).

[31] AWWA, APHA, WPCF, Standard Methods for the Examination of Water and Wastewater, Washington, (1989).

[32] Li, W., Hua T., Zhou, Q., Zhang, S., Li, F., "Treatment of stabilized landfill leachate by the combined process of coagulation/flocculation and powder activated carbon adsorption", Desalination, 264(12):56-62, (2010).

[33] Ishak, A. R., Hamid, F. S., Mohamad, S., Tay, K.S., "Stabilized landfill leachate treatment by coagulation-flocculation coupled with UV-based sulfate radical oxidation process", Waste Management, 76: 575-581, (2018).

[34] Tepe, O., Tunç, M.S, "Optimization of coagulation process using of response surface methodology for leachate treatment”, Eurasia Waste Management Symposium, Istanbul/Turkey, 870-876, (2016).

[35] Bashir, M.J.K., Xian, T.M., Shehzad, A., Sethupahi, S., Aun, N.C., Abu Amr, S., "Sequential treatment for landfill leachate by applying coagulation-adsorption process", Geosystem Engineering, 20(1): 9-20, (2017).

[36] Daud, Z., Awang, H., Latif, A.A.A., Nasir, N., Ridzuan, M.B., Ahmad, Z., "Suspended solid, color, COD and oil and grease removal from biodiesel wastewater by coagulation and flocculation processes", Procedia Social and Behavioral Sciences, 195: 2407-2411, (2015).

[37] Guo, J.-S., Abbas, A.A., Chen, Y.-P., Liu, Z.-P., Fang, F., Chen, P., "Treatment of landfill leachate using a combined stripping, Fenton, SBR, and coagulation process", Journal of Hazardous Materals, 178(1-3): 699-607, (2010).

[38] Verma, S., Prasad, B., Misha, I.M., "Pretreatment of petrochemical wastewater by coagulation and flocculation and the sludge characteristics", Journal of Hazardous Materials, 178(1-3): 1055-1064, (2010).

[39] Rodrigues, C.S.D., Neto, A.R., Duda, R.M., de Oliveira, R.A., Boaventura, R.A.R., Madeira, L.M., "Combination of chemical coagulation, photo-Fenton oxidation and biodegradation for the treatment of vinasse from sugar cane ethanol distillery", Journal of Cleaner Production, 142(4): 3634-3644, (2017).

[40] Daud, Z., Latif, A.A.A., Rui, L. M., "Coagulation-flocculation in leachate treatment by using ferric chloride and alum as coagulant", International Journal of Engineering Research and Applications, 2(4): 1929-1934, (2012). 